(6)

\section{OPEN ACCESS}

${ }^{1}$ Department of Marketing University of Stirling and the Open University, Stirling, UK ${ }^{2}$ Department of Marketing, Institute for Social Marketing, University of Stirling, Stirling, UK

\section{Correspondence to}

Professor Gerard B Hastings, Department of Marketing, University of Stirling and the Open University, Stirling FK9 4LA, UK

gerard.hastings@stir.ac.uk

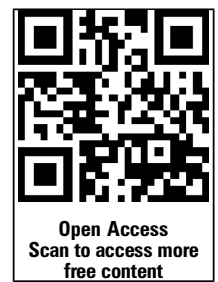

CrossMark

To cite: Hastings $\mathrm{GB}$, Moodie C. Tob Control 2015;24:ii1-ii2.

\title{
Death of a salesman
}

\author{
Gerard B Hastings, ${ }^{1}$ Crawford Moodie ${ }^{2}$
}

\section{TAKING THE LEAD}

In December 2012 Australia became the first jurisdiction to mandate plain (or standardised) packaging for tobacco products. Many governments have been looking on with interest, anxious to learn if this is also the next step forward in their own efforts to tackle the harms caused by tobacco. This special issue begins to answer this question by presenting a series of studies which provide an initial evaluation of the policy. What have been the early impacts of plain packaging on young people and adult smokers? And are there any unintended consequences-has it reduced prices, for instance, or encouraged illicit tobacco use?

\section{THE LAST WORD IN TOBACCO MARKETING?}

Plain packaging is the latest of many moves by policy makers to constrain tobacco marketing. It is over 50 years since the first tentative steps were taken, typically picking off TV advertising, but it was not until this century that the need for controls to be comprehensive was fully appreciated. Market forces, it became clear, dictate that any gaps will be exploited and promotional budgets moved to unregulated channels. The pack itself is one of the last of these promotional fall-backs. In recent years the literature has documented a seemingly endless flow of elaborate packaging innovations. It has also demonstrated how tobacco companies have used the pack to promote their products, mislead consumers about the harmfulness of smoking, and undermine the legally mandated health warnings. So even in markets that are otherwise dark, packaging continues to offer tobacco companies a glimmer of light, providing a last channel for conveying image, symbolism and brand meaning. ${ }^{1}$

\section{FROM THEORY INTO PRACTICE}

Until recently the evidence base for plain packaging has, perforce, been hypothetical. Australia's lead has now delivered a real world natural experiment. The real world, of course, is messy and natural experiments less neat than custom-designed ones. As such, it remains a challenge for researchers, particularly as plain packaging has been part of a wider package of measures introduced by the Australian Government, including larger health warnings, mass media campaigns and tax increases. Separating out the effects of each can prove difficult-it was ever so. Nonetheless, the picture to emerge from the papers in this special issue suggests that plain packaging is delivering on its hypothetical promise, and the potential downsides, much vaunted by its opponents, are not materialising.

\section{THIS ISSUE UNPACKED}

The evidence suggests that plain packaging is severely restricting the ability of the pack to communicate and create appeal with young people and adults. ${ }^{2-4}$ For instance, school-based surveys with students aged 12-17 year in 2011 and 2013 show that the removal of branding and uniformity of pack appearance has increased negative pack ratings and decreased positive ones. ${ }^{4}$ Cognitive processing of the health warnings did not change, however, suggesting that pack appearance is more relevant to young people than are the warnings. ${ }^{5}$

A number of studies with adult smokers point to plain packaging fulfilling its core aims of reducing appeal, particularly among young adults, and increasing warning salience. ${ }^{3}$ In a cross-sectional tracking survey of cigarette smokers, plain packaging was associated with increased thinking about quitting and quit attempts. ${ }^{6}$ In addition, dislike of the pack, lower satisfaction from cigarettes and attributing motivation to quit to the warnings predicted daily thoughts of quitting. ${ }^{7}$ These findings may also help to explain why smokers were more likely to conceal their packs in outdoor venues after the introduction of plain packaging. ${ }^{8}$ Research with adults is not confined to cigarette smokers either, with a mixed methods study suggesting that the benefits of plain packaging may also extend to cigar and cigarillo smokers. ${ }^{2}$ A lesson perhaps for those governments (eg, Ireland, UK) planning to exclude such products from plain packaging legislation.

These findings highlight the potential impacts on adult smokers, a group often overlooked in the plain packaging debate. Clearly, prevention is better than cure, which is why stopping new generations from starting to smoke is a key objective of plain packaging, but adult smokers are also an important potential target. That they are amenable to change is beyond question: in Australia (as in many other markets) there are more ex-smokers than current smokers. These studies suggest that plain packaging can play a role in encouraging this transition.

This issue also examines whether plain packaging has had any unintended consequences. Did it lower prices for licit tobacco or increase the use of illicit tobacco, both of which might be expected to encourage smoking? There is no evidence for either effect. ${ }^{9-12}$ A review of retail magazines, for instance, shows that following the introduction of plain packaging, average inflation-adjusted recommended retail prices actually increased for cigarettes in all price segments (value, mainstream and premium). ${ }^{10}$ The rise in cost was greatest for cigarettes in the mainstream and premium segments, which may, in part, help explain the shift to value 
brands. ${ }^{11}$ As for the source of retail purchase, there was no decline in the percentage of smokers purchasing from convenience stores and no indication of increased purchase from overseas, online or duty-free. ${ }^{13}$ And in contrast to the findings from the tobacco industry commissioned KPMG report, ${ }^{14}$ there was no evidence of an increase in the consumption of illicit 'cheap white' $^{\text {cigarettes. }}{ }^{12}$

\section{WHAT WILL HAPPEN IF GOVERNMENTS DO NOT ACT?}

This issue is focused on what happens when plain packaging is introduced, but it is instructive to consider what is likely to occur in markets where government does not act and the status quo prevails. The pack will continue to be used as a marketing channel and innovations will proliferate. New pack structuressizes, openings, construction materials-are inevitable. Beyond visual appeal we are also likely to see: packs with special foils, varnishes or coatings that create distinct tactile experiences; audio packs that play pre-recorded messages, music or other noises, which are already available for some other products ${ }^{15}$; and packs which release fragrances (which are already patented by tobacco companies). Inks will also have an important role to play in future on-pack marketing, with phosphorescent 'glow in the dark' inks having already appeared on cigarette packs in some markets, and packs with photochromic (light-sensitive), thermochromic (heat-sensitive) or oxygen-sensitive inks likely to follow. Although only for display purposes, photochromic Camel packs which change colour appeared in retailers in the Netherlands in 2014. Conductive inks, which enable printed electronics technology and the incorporation of cheap electrical circuits into cardboard are also opening up a world of marketing opportunities. ${ }^{16}$ Cartons of Kent cigarettes, with circuit boards and touchpads enabling scrolling on-pack messages, have already appeared in duty-free outlets in Asia. As technology advances, it is possible that printed electronics may be applied to deliver moving images on tobacco packaging. Similarly, we may see cigarette packs capable of digitally communicating with consumers and allowing connectivity to their virtual worlds via smart devices (smartphones, smart watches, smart glasses).

Whatever directions these innovations take, it is clear that the marketing power of the pack is only going to increase. So governments which do not act on plain packaging today will have a bigger problem to tackle tomorrow.

\section{A CASEBOOK EXAMPLE}

Plain packaging in Australia has been a casebook example of effective tobacco control-a policy measure driven by evidence, carefully designed and implemented, and now rigorously assessed. Further, it is set within the context of wider Australian tobacco control, reinforcing the most basic lesson learned over the last half century: action has to be strategic and comprehensive. There are no silver bullets. This issue demonstrates that plain packaging is beginning to deliver on its promise, and an important step forward, but it is still only part of the solution. Australia has learned and applied this lesson well and that is why it has one of the lowest smoking prevalence rates in the world.

\section{Competing interests None.}

Provenance and peer review Not commissioned; internally peer reviewed.

Open Access This is an Open Access article distributed in accordance with the Creative Commons Attribution Non Commercial (CC BY-NC 4.0) license, which permits others to distribute, remix, adapt, build upon this work non-commercially, and license their derivative works on different terms, provided the original work is properly cited and the use is non-commercial. See: http://creativecommons.org/ licenses/by-nc/4.0/

\section{REFERENCES}

1 Underwood RL, Ozanne JL. Is your package an effective communicator? A normative framework for increasing the communicative competence of packaging. J Mark Commun 1998:4:207-20.

2 Miller C, Ettridge K, Wakefield M. Research paper: "You're made to feel like a dirty filthy smoker when you're not, cigar smoking is another thing all together." Responses of Australian cigar and cigarillo smokers to plain packaging. Tob Control 2015;24:ii58-65.

3 Wakefield M, Coomber K, Zacher M, et al. Australian adult smokers' responses to plain packaging with larger graphic health warnings 1 year after implementation: results from a national cross-sectional tracking survey. Tob Control 2015;24:ii1725.

4 White V, Williams T, Wakefield M. Has the introduction of plain packaging with larger graphic health warnings changed adolescents' perceptions of cigarette packs and brands? Tob Control 2015;24:ii42-9.

5 White V, Williams T, Faulkner A, et al. Do larger graphic health warnings on standardised cigarette packs increase adolescents' cognitive processing of consumer health information and beliefs about smoking-related harms? Tob Control 2015; 24:ii50-7.

6 Durkin S, Brennan E, Coomber K, et al. Short-term changes in quitting-related cognitions and behaviours after the implementation of plain packaging with larger health warnings: findings from a national cohort study with Australian adult smokers. Tob Control 2015;24:ii26-32.

7 Brennan E, Durkin S, Coomber K, et al. Are quitting-related cognitions and behaviours predicted by proximal responses to plain packaging with larger health warnings? Findings from a national cohort study with Australian adult smokers. Tob Control 2015;24:ii33-41.

8 Zacher M, Bayly M, Brennan E, et al. Personal pack display and active smoking at outdoor café strips: assessing the impact of plain packaging 1 year postimplementation. Tob Control 2015;24:ii94-7.

9 Scollo M, Bayly M, Wakefield M. The real world advertised prices of cigarette packs in retailers before and after the implementation of plain packaging: a repeated measures observational study. Tob Control 2015;24:ii82-9.

10 Scollo M, Bayly M, Wakefield M. Did the recommended retail price of tobacco products fall in Australia following the implementation of plain packaging? Tob Control 2015;24:ii90-3.

11 Scollo M, Zacher M, Durkin S, et al. Changes in use of types of tobacco products by pack sizes and price segments, prices paid and consumption following the introduction of plain packaging in Australia. Tob Control 2015;24:ii66-75.

12 Scollo M, Zacher M, Durkin S, et al. Use of illicit tobacco following introduction of standardised packaging of tobacco products in Australia: results from a national cross-sectional survey. Tob Control 2015;24:ii76-81.

13 Scollo M, Coomber K, Zacher M, et al. Did smokers shift from small mixed businesses to discount outlets following the introduction of plain packaging in Australia? A national cross-sectional survey. Tob Control 2015;24:ii98-100.

14 KPMG. Illicit tobacco in Australia. London: KPMG LLP, 2014.

15 Moodie C, Angus K, Ford A. The importance of cigarette packaging in a dark market: the 'Silk Cut' experience. Tob Control 2014;23:274-8.

16 Mance $\mathrm{H}$. Could printed electronics be getting a cigarette break? Financial Times 12 July 2012. http://www.ft.com/cms/s/0/247561ba-cc09-11e1-839a-00144 feabdc0.html\#axzz3PkyiJ8DN 